\title{
Intention, barriers and opportunities to exit from commercial sex work among female sex workers in Ethiopia: Qualitative study
}

\author{
Mazeingia $\mathrm{YT}^{1}$, Negesse $\mathrm{A}^{2}$ \\ ${ }^{1}$ Debre Markos University, Ethiopia ${ }^{2}$ Hawassa University, Ethiopia
}

\section{ABSTRACT}

Introduction: Commercial sex work exposes women to countless risks and exit is often recommended as an essential strategy to evade associated risks. The intentions to exit can predict commercial sex workers' motivation towards the detachment of the sex work.

Objectives: The purpose of this study is to explore intention, barriers, and facilitating situations to exit from commercial sex work among female sex workers in Dire Dawa, Ethiopia.

Methods: We conducted qualitative research among 18 female sex workers using in-depth interview. The data collection was done in the local language, we transcribed the recorded data and translated it to English before exporting to ATLASti7 to facilitate the data analysis process. We used respondent driven sampling to recruit study participants. We implemented an inductive thematic analysis approach for the data analysis.

Results: The women had a strong intention to exit. They intended to give up on commercial sex work. Certain barrier needs to be addressed such as financial insecurity, social stigma, and discrimination, skill gap, lack of support, and poor education status before their successful exit. The need for financial supports to open a private business and strong motivation was identified as one of the opportunities for a successful exit from commercial sex work.

Conclusion: Women had a strong intention to exit from commercial sex work, but equally demanded support for alternative livelihood. It is important that government and other stakeholders need to provide comprehensive support to commercial sex workers like financial support, filling in the skill gap and improving poor saving habits through training, and establish functioning rehabilitation centers for drug addict women.

Key words: Barriers, commercial sex work, intention, opportunities

DOI: https://doi.org/10.3126/ijosh.v10i1.29885

\section{Introduction}

C ommercial sex worker (CSW) is an individual who practice sexual intercourse for an exchange of money or goods. ${ }^{1}$ Women enter into CSW life for various reasons and stay in the business for years whether they experience risks or not. ${ }^{2}$ CSW is exposed to various risks like Sexually Transmitted Infections(STI)/ Human Immunodeficiency Virus (HIV), violence, drug

Date of submission: 22.05 .2020

Date of acceptance: 10.07 .2020

\section{Corresponding Author}

Yohannes Teka Mazeingia

$\mathrm{MPH}$ in Reproductive Health

Lecturer, Debre Markos University

Ethiopia.

Email: Yoniteka23@gmail.com

Tel: +251939698968 addiction, social stigma and arrest. ${ }^{3-8}$ Despite women perceive CSW as a hazardous lifestyle, the majority of them continue to spend years in this risky business. ${ }^{9}$

Numerous risk prevention strategies are implemented in different settings to minimize risk to the commercial sex worker. Comprehensive and integrated approaches including behavioral change and communication, provision of sexual and reproductive health services and violence prevention approaches are commonly recommended to minimize threats of CSW. ${ }^{2,10}$ Some countries emphasize on legalizing and decriminalizing of CSW to create better working environments for commercial sex workers. ${ }^{9}$ Moreover, researchers recommend on approaches to minimize

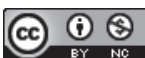

This journal is licensed under a Creative Commons AttributionNon Commercial 4.0 International License. 
entry to commercial sex work by alleviating situations which forces women to enter into CSW. ${ }^{11,12}$ Exit from commercial sex work is also advocated as an essential component to minimize risk to those who are already in the business. ${ }^{2,13}$

The theory of planned behavior identifies that intention towards a particular behavior is the proximate predictor of behavioral practice. ${ }^{14}$ Even if commercial sex work is risky for women, not all of them have the intention to exit from this hazardous life. ${ }^{15}$ The level of intention to exit from CSW varies across individual women. ${ }^{15,16}$ Some commercial sex workers particularly those who enters to the CSW due to the loss of their significant others or because of disputes within family members, might contemplate commercial sex work as their destination and the only option of survival. ${ }^{17}$ Some features of commercial sex work including its freedom, easy money, and enjoyable social and working environment influences women to stay in the CSW for a longer duration. ${ }^{18}$ Besides, some women intend to exit from CSW if they have secured an alternative sustainable source of income once they exit from the commercial sex work. ${ }^{7}$ It is challenging for the women to stay out of commercial sex work despite their determined exit and are found returning to the work after a short duration. ${ }^{19}$ The reason is that the money generated through CSW is much higher than what they could make through other available jobs for example, commercial sex worker finds other jobs as labour jobs such labour is not sufficient to meet their demands. The exploration of such concepts during the exit process can enable program planners to get deep insight on required planning for the exit strategies.

Women trying to give up on the commercial sex work require support from multiple agencies as the exit process is often tough and lengthy. ${ }^{15}$ The decisions to stop CSW are subjective to the quality of life they enjoy with and without commercial sex work. ${ }^{17}$ Several factors influence women's exit from commercial sex work positively and negatively and these can be individual, relational, structural, and societal factors. ${ }^{15}$ Therefore, exploring such barriers and opportunities to exit from CSW is crucial to design projects for supporting effective exit processes.

Though there were numerous researches conducted on the exit from commercial sex work, majority of previous studies are directed towards street commercial sex workers. ${ }^{15-17,20}$ Theoretical models and information on exit from commercial sex work generated from street prostitutes might not be applicable for other typologies of commercial sex workers like venue-based, phonebased, home-based, and internet-based CSW. ${ }^{15}$ Moreover, majority of such prior researches on exit from CSW were conducted in settings with the strong social welfare system and where women got support from different supporting agencies including from rehabilitation centers, counseling service, sex worker associations, and other organizations which facilitated their exit process from commercial sex work. ${ }^{9,15,21-23}$ Inaccessibility and unavailability of such supports for the female sex workers in developing countries like Ethiopia hinder their exit process. Studies conducted in such settings and incorporating other typologies of commercial sex work might be useful to explore concealed features of the exit process and barriers which women encounter as challenges to the exit from CSW. The, purpose of the study is to explore intention, barriers, and facilitating situations to exit from commercial hinders sex work among current female commercial sex workers in Dire Dawa, Ethiopia.

\section{Methods}

The study was conducted in Dire Dawa town, Eastern Ethiopia. Dire Dawa is the second largest urban center in Ethiopia after Addis Ababa. The central statistical agency during 2017 estimated the female population of 146000 in the city. Though recent estimates on commercial sex work was not available, number of female sex workers in Dire Dawa town a few years back was estimated of $586 .{ }^{24}$ For this study, we conducted a thematic analysis qualitative study among 18 commercial sex workers from February 1 through March 30, 2016.

We recruited study participant commercial sex workers with respondent-driven sampling method. ${ }^{25}$ Four commercial sex workers were recruited from different typologies of commercial sex work. The first four female sex workers recruited other commercial sex workers and one study participant was allowed to recruit two commercial sex workers for the study. ${ }^{25,26}$ The process proceeded likewise until we attended a theoretical sample of 18 .

The qualitative data collected through in-depth interviews using local language and interviews ranged from thirty-four minutes to one and a half hours. We used semi-structured interview guide to facilitate the data collection process. The interview guide included questions to address issues for assessing female 
sex workers' demographic characteristics, how they entered into CSW. What risks did they experience in commercial sex work? What was their desire to stop commercial sex work? How did their previous exit experience look like? What barriers did they experience in their previous exit attempt? What facilitator situations did they experience to exit from commercial sex work? What internal and external influence they had to exit or to stay in commercial sex work?

The audio recorded data was transcribed and translated to English. The translated data was exported to ALASTi7 software to facilitate the data analysis process. We used an inductive thematic analysis approach and the data analysis conducted concomitantly with the data collection. We operationalized the following terminologies as.

Commercial sex worker (CSW):- is a woman who practices sexual intercourse for exchange of money or good.(1)

Intention to exit from commercial sex work: The likelihood to stop commercial sex work passing the challenges they will experience in the coming one year.

All women went through a verbal informed consent process that involved two stages. Once they were requested to participate though the recruiter individual, the interviewer verified various issues for them including about the purpose of the study, how respondents' identity would be kept anonymous, what would happen with audio recordings, issues of confidentiality and privacy, risks and benefits of participation on the research and who would access interviews. Then the interviewer scheduled an appointment to conduct the interviews for those who volunteered to participate in the study. Moreover, verbal consent was taken before conducting the interviews. Written informed consent was not opted because of the need to ensure anonymity and to address the participants' concerns to avoid any formal identification with a research project in the sex industry. The principal investigator obtained ethical clearance from Haramaya University College of Health and Medical sciences, the institution of health research ethical review committee.

\section{Results}

\section{Exit from commercial sex work}

Eighteen CSWs participated in the study with a mean age of 18.4 years. Except for one, all study participants had formal education which varied from grade three to vocational training graduates. Ten of the eighteen CSWs had at least one child. They worked as commercial sex worker for years ranging from one to ten years. From the eighteen CSWs three were street-based, five were phone-based, two were home-based and eight of them identified themselves venue based CSWs. Moreover, two of the study participants identified themselves as HIV positive.

Intention to exit: All study participant commercial sex workers intended to exit from CSW in the near future. The majority of them also inferred that their decision could fail unless they would get external assistant from stakeholders including government, local community and family. The women planned to use two strategies to exit from commercial sex work. Marriage emerged as a major strategy for women to give up commercial sex work. Not all women desired marriage to building a happy family rather they planned to use marriage as an escape mechanism from the troubles they face in CSW. Such women were found ready to marry even adulterous men knowing they have legal marriage. Although this could be an escape strategy to these women but chances are high regarding the return to $\mathrm{CSW}$ if the marriage ends in a divorce.

"... I will not hesitate to stop this life. Ehhh (feel amazed for the question). Even I am eager to live with an elderly man who lives with fecal incontinence due to age. I will marry such men and serve as his wife if he allows for me to live with him. My words are true; I swear with the name of God. The life that I live shouldn't be mentioned as real life. Ehhhhh this is not life at all... A"

Owning private small businesses and securing other means of income emerged as an alternative strategy to exit from CSW. They discussed the financial problem as a major constraint to run a private business, though the businesses they planned to open demanded little capital. Some participants have began saving money and others have planned to save from what they got from CSW to meet their future financial demand. Others wished to get financial support from different stakeholders like loaners, supporting agencies and local administration. But the extravagant behavior in CSW life is a major obstacle to save money from what they get through commercial sex work or other means planning to start a new business.

"... Recently I thought to save money and start my own business. I spent money a lot since I love enjoyment and fun. I want either to run my own beauty salon or to 
recruit in a beauty salon once I get professional training ..." D

“... I told them to support me financially to buy a refrigerator, packed water, and beverages when they requested me what I wanted to work if I will stop commercial sex work. I promised to them as I will change myself in a day if they support me to buy refrigerator..." E

\section{Barriers to exit from commercial sex work}

Women are often forced to encounter multidimensional and complex hurdles while they intended to exit and after exit from CSW. Those barriers are compiled in three major themes.

\section{Individual barriers}

It was found that women entered into commercial sex work dropping from school mostly before they completed their high school. Their deprived educational status has hindered them to participate in financially viable job opportunities. Moreover, they had a professional skill gap to work in other job opportunities. Lack of skill and poor educational status has influenced them not to initiate exit and even to resume CSW once they had stopped it earlier.

“... My stepfather punched me to study hard and to be brave in my education. He would kick me if I missed one of his questions. But I only studied to show for him, I had no interest in education. I always remember his carriage to let me a good student, he tried hard to support me though I did not understand him. If I continued my education, I could do various things stopping commercial sex work..." D

Substance abuse emerged as another subtheme identified as an individual barrier for women stopping exit from CSW. Commercial sex workers exposed to substance abuse problems imposed women to spend the majority of their money on drugs. These substance abusing women felt that they could not give up commercial sex work unless they overcome their addiction either by giving up their addiction or securing financial power to buy drugs once they exit from commercial sex work.

"... Once we stop commercial sex work, we need to give up on our addiction problem and put our focus on our work; otherwise we cannot focus on our work. For example if you look at me I have addiction problem when I wake up from sleep, I need to drink alcohol at early morning. But if I have a work to do, I need to stop my desire for alcohol at least until I will finish my work. I have a serious alcohol addiction; I want to drink the whole day if I got someone who can invite me a drink. It is very difficult to give up on addiction, how I can stop my addiction problem. Let God allow for us to be free of addiction, otherwise it is hard to stop this life..." $E$

Women who had tried to exit from commercial sex work through marriage and divorce have influenced them to resume commercial sex work. Once women got married, they would stop supporting their family financially and rather they put the financial burden on their husband. Such dependency trends and lack of involvement on income generating activities after marriage have influenced women to not exit from commercial sex work permanently.

"... I dated someone and I started to live with him for short period of time. But I resumed sex work when we broke up. I had no money to run other works, even my ex-boyfriend was not better than me financially. That is why I resume commercial sex work again..." $L$

The women reported of experiencing various challenges after their temporary exit and they would start missing commercial sex work when they failed to manage emerging challenges. Besides they were also attached to good memories they had as commercial sex workers which includes joy, freedom, drugs and alcohol. The women felt that commercial sex work served as a right place to hide obstacles faced after the exit. The women reported of swinging in and out of commercial sex work.

"... I started to miss many things from commercial sex work like dating different men, drinking daily until I become drunk. I missed many things when I spent the day sitting at home. I got money and spent it without any tension. I had taken any drug including Hashish and alcohol as I wanted before I had stopped commercial sex work. So these things exert great influence on me to resume this work. Once I resumed commercial sex work, I just wanted to stay in that life for some period of time, but I immersed in it for years leaving no option to stop it again..." A

\section{Financial barriers}

Commercial sex workers were paid well but the women failed to save from their earning. Such poor saving habit has weakened their exit due to looming financial insecurities. Women felt a lack of financial power to start their desired small private business enterprise. Moreover, such financially insecure situations are 
exacerbated with low payment for accessible jobs and cost inflation in the external working environment. Such that the women preferred continued working as commercial sex workers than suffering from financial problems.

"... How could I stop this life having nothing at hand; I will stop it only if I secure other means of income. I never try to stop commercial sex... It is very hard to lead life with little money I can make out there. I also will not stop this work unless I got better thing than the life I am currently living. If they support us to run enterprises in group with other female sex workers and give us Ioan, I will stop this work..." C

"... I can tell you definitely I will not hesitate to stop sex work if I got support either from government or other individuals. Unless I get someone to support me, it is difficult for me to lead life with little money since I made money daily here... I feel angry on myself for not saving money. I know older female sex workers who live with joy out there since they buy house and have good deposit at bank. I feel sorry for myself and perceive as I might be like those women if I saved some money from what I get. Any women wish to live out of sex work..." Sa

\section{Psychosocial Barriers}

The final theme of barriers to exit from commercial sex work is psychosocial problems which women experiences when they think to exit from the business. Women might stop commercial sex work, but they were treated as a prostitute and stigmatized by the local community. Local community including their partners disrespected commercial sex workers and this was identified as the major social challenge for women after their exit. Some of them also reported of experiencing violence for their association with the sex trade. Such social implications scared women to not stop CSW from fearing to socialize with the local community.

"... The society did not forget our history. The act of not forgiving me for my previous mistakes in commercial sex work observed even on the man whom I date... My partner is the one who first disrespects me for who I was. I believe he liked me when he accepted who I am and start to live with me. But this man even started to talk about my past life, when there is a dispute between the two of us. I became angry when he said, 'do you forget from where I bring you to this life?' Even his mother spoke loud to other individuals 'my son marries this prostitute.' His families also stigmatized my partner when we two had a relatively good relationship. Since he is a human being, he might feel sad with their act, I cannot say why he feels like that. These scenarios forced me to hate the external environment..." $M$

Besides stigma and discrimination, women described of lack of adequate support from various supporting agencies during and after their exit from commercial sex work. They demanded support including acceptance by the community, financial support as a loan from the government or small scale loaners, respect from partners, and solving disputes with negotiation and support from other commercial sex workers to stop their negative influence. Lack of such supports possibly hinders women's exit from commercial sex work. Moreover, women reported waiting for supporters to come and requested them what they demanded rather than searching for available supports they could access.

"... There is a huge influence from my friends to let me resume commercial sex work, while I stop it for some time. They say, "Why do you collect one and two birr with your hand which adapts to hold hundred birrs, this is the influence of your boyfriend why not you leave him and resume your enjoyable life. They do not allow me to live far from this life; they do not want me to stop commercial sex work. In times I stay home and stop moving out to search for clients, they will influence me to go with them and enjoy as I did before. They will ask us what is wrong with me while I stay home for days..." $B$

"... It was difficult actually, only God supported me by the time I stay out of this life. I independently challenged the financial problem I faced once I stop it. If I got one person who could support me, I exit from this work permanently. Life is not easy as we thought; it is very tough to raise children with some money now a days. If I have no one to support, it might not be as such problematic to lead a life with the money I have..." $F$

\section{Opportunities to exit from commercial sex work}

Though women face several barriers and challenges for their exit from CSW, there were also opportunities which could facilitate their exit smoothly. These facilitator are discussed in the following three themes.

Psychosocial factors: Women have developed strong intention to give up on CSW and overcome challenges they might experience during and after exit from commercial sex work. The women were found very motivated to lead a life out of CSW. They had 
a great ambition to fix problems and live a better life once they give up on commercial sex work. Besides, they believed they would not be influenced by external influences exerted from different situations which could impede their exit process, if they got real opportunity to give up on commercial sex work.

"... What are you talking about? Nothing is as fascinating as making money with your effort and supporting life through normal work. I am excited to get money exerting my full effort until I sweat, instead of leading life this way practicing this horrible work. I suggest other commercial sex workers to do so..." $G$

Individual factors: Though their substance abuse problem coupled with lack of rehabilitation center was a major constraint to exit from commercial sex work, the majority of them had a strong desire to give up on their substance abuse behavior. Many women were confident as they could stop consuming addictive substances if they could get an exit from commercial sex work. Besides, not being a substance abused person was also reported as a big opportunity for some commercial sex workers.

“... I will not care about satisfying my addiction desire if I decide to stop this work. It does not influence me to not exit from this life. I can stop using those drugs if I will quit from sex work. I saw many things in my life so it will not be difficult to stop khat and cigarette for me..."N

"... No these things (substance abuse) do not affect me. You know why, I chew khat occasionally, though I need to drink alcohol and smoke Shisha after I chew khat. Moreover, these addiction-related problems are common here in Dire Dawa, so I might use these substances whether I participate as a commercial sex worker or not, it is up to me to decide on that. I will not be influenced by addiction problems..." I

Having a child was identified as the other facilitator for women to exit from commercial sex work and they reported have developed a strong desire to exit from commercial sex work for their kids. They also feared the situation of supporting family including children which might force them to re-enter sex trade.

“... Though I might not support my children prolonging my life will help them to say at least they have a mother. I do not want my children's mentality to be hurt with loneliness. It is better to have a mother alive though she is not able to do anything for them rather than saying my mother is dead. When I thought about such things, I believe it is better to exit from this life..." S

Work-related situation: Though women's educational status is a major obstacle for their recruitment in financially safe jobs, many of them believed that they could work various jobs either individually or encompassed in group enterprises. Besides the business, they intended to run demanded little initial capital which would not be difficult for small scale loaners and supporting agencies. It was reported that none of such financial donors have accessed them for their support for exiting commercial sex works.

"... I just saved a little amount of money from the bonus I got while I worked as a waiter. Thanks to God, I started to sell local coffee with that money I saved. It is not hard for me to stop sex work and start another business. Actually selling local coffee is not my final target, I want to do better business than selling local coffee. I do not want to look at my self tomorrow selling coffee like I do today. I will add on the money I have today and begin other businesses. Actually, if I prepare the coffee well, I will have many customers. It is all about neatness and quality of the coffee I will prepare which matter the number of my customers..." $K$

\section{Discussion}

Women participates in CSW for survival and exit from commercial sex work is difficult unless they secured options to support their family financially. Lack of social welfare to support ex-commercial sex workers have exerted undeniable challenge on women for their exit from CSW. Decisions to stop commercial sex in such situations have exposed women to suffer from poverty. Therefor women prefer to stay in CSW although they wish to discontinue. They would successfully exit from commercial sex work if they could get financial support to run small private businesses which could support them to cover their basic needs.

Women might believe that they could perform planned behavior with the available resources and opportunities they had. ${ }^{27}$ Perceived behavioral control in theory of planned behavior clarified practicing a particular behavior is not dependent on women's intention alone; there are issues out of her control which can influence the exit process of commercial sex workers. ${ }^{14}$ Besides, researches has identified that exit from commercial sex work is difficult for women due to persistently strong sense of responsibility for the economic wellbeing of 
their families. ${ }^{28}$

Commercial sex workers are better paid than other job but it is an uncommon practice in these sex workers to save money and start their desired private business. Poor saving habits in commercial sex work due to high expense on self and spending money for drugs are also discussed in previous studies. ${ }^{29,30}$ Such an extravagant behavior exert serious financial problem on CSW both during exit and once they stopped commercial sex work. This effect is observed much worse on excommercial sex workers since their income decreases considerably as compared to what gets during their CSW.

Marriage was identified as the strategy for women to escape from CSW and it had a great effect on their exit process. Financial dependency inside marriage on their husband once women exit was a huge barrier for not involving in commercial sex work and it has influenced them to resume CSW when they experienced a divorce. Women need to look for other sources of income rather than relying only on the support they got from their partners. Even some of them used marriage as a temporary break away from commercial sex work. Though other researches have discussed an emotional relationship like falling in love is used as a facilitator of exit and to let them exit emotionally, women do not use romantic relationships as a strategic option to escape from commercial sex work. ${ }^{15,31,32}$ Such a reactionary type of exit do not enable women to stop commercial sex work permanently. ${ }^{32}$

The influence of drug addiction has served as a barrier to exit from commercial sex work in two aspects in previous studies. ${ }^{29}$ Women might enter to CSW to buy drugs for their addiction and they prefer to stay in sex worker's life to meet their addiction. ${ }^{32}$ Secondly, women might not be able to give up their addiction when they try to exit from commercial sex work and this has exerted greater problems for them to find money to cover for drugs, which has influenced them to resume CSW. ${ }^{32}$ Besides researches have revealed that lack of rehabilitation centers had a great impact on women to not exit from CSW. In this study, the effect of substance abuse on exit from commercial sex work was explained by their non-existent saving which also affects their aspiration of opening a private business. The substance-abusing CSW faced such challenges and hoped that they could manage their addiction if they received financial support to open a private business. The minimal influence from substance abuse might be because Khat and shisha, the most consumed addictive substances used by study participants have lesser effects compared to is intravenously and nasally consumed drugs.

Formal services from supporting agencies including professional training, safe housing, and individual and group counseling are crucial to facilitate exit from CSW particularly during the initial exit phase. ${ }^{22,31,33}$ The sex workers require more help and support than their social network was able to offer. ${ }^{34}$ Not only formal support but informal support from the local community also facilitates exit from commercial sex work. ${ }^{15,19}$ Women in the current study did not access such formal supports and experienced stigma from the local community and were demoralized by others even if they stopped CSW. Such social behaviors inhibits women to exit effectively and pushes them to resume commercial sex work.

This study had a few limitations. Unlike earlier studies, we did not incorporate the opinions of the excommercial sex workers women, and these women might have different exit experiences. Moreover, we have explored exit experience in situations where women did not get any formal support, so projects planned to support women's exit process might observe issues which have not been addressed in this research. The study has tried best to get trustworthy data from study participants, however, the cultural norm towards CSW in the study setting might have influenced their response. The finding of this research might not be transferable in some other setting where CSW is legal and socially acceptable.

The commercial sex workers had a strong desire to give up on CSW, but in developing countries like Ethiopia, the exit from commercial sex work is difficult. These difficulties are faced by women due to a lack of social welfare systems, financial insecurity, and social stigma and discrimination. It is therefore recommended that the stakeholders need support women to enable them to exit effectively from commercial sex work.

\section{Acknowledgments}

We would like to thank study participants, without their participation and the information we got from them our plan to conduct this study would not be applicable.

\section{Declarations}

\section{Ethics approval and consent to participate}

The research team received an ethical approval letter 
from Haramaya University Institution of health research ethical review committee. Informed consent was taken from each study participant before the study.

\section{Availability of data and material}

The datasets generated and/or analyzed during the current study are not publicly available since it consists of sensitive information about the study participants

\section{References}

1. UNAIDS. Guidance note on HIV and sex work. 2009.

2. WHO. Prevention of HIV among sex workers in Sub Saharan Africa: literature review. WHO press. 2011.

3. Shannon K, Strathdee SA, Goldenberg SM, Duff P, Mwangi $P$, Rusakova M, et al. Global epidemiology of HIV among female sex workers: influence of structural determinants. The Lancet. 2015;385( 9962):55-71.

4. Beattie TS, Bhattacharjee P, Ramesh B, Gurnani $\mathrm{V}$, Anthony $\mathrm{J}$, Isac $\mathrm{S}$, et al. Violence against female sex workers in Karnataka state, south India: impact on health, and reductions in violence following an intervention program. BMC Public Health. 2010;10(476).

5. Alemayehu M, Yohannes G, Damte A, Fantahun A, Gebrekirstos K, Tsegay R, et al. Prevalence and predictors of sexual violence among commercial sex workers in Northern Ethiopia. Reproductive Health. 2015;12(47)

6. Deering KN, Amin A, Shoveller J, Nesbitt A, GarciaMoreno C, Duff $P$, et al. A Systematic Review of the Correlates of Violence Against Sex Workers. American Journal of Public Health. 2014;104(5):e4254.

7. Mbonye M, Nalukenge W, Nakamanya S, Nalusiba B, King R, Vandepitte J, et al. Gender inequity in the lives of women involved in sex work in Kampala, Uganda. Journal of International AIDS Society. 2012;15(1).

8. Ross M, Crisp B, Månsson S-A, Hawkes S. Occupational health and safety among commercial sex workers. Scand J Work Environ Health. 2012;38(2):105-19.

9. Swendeman D, Fehrenbacher AE, Ali S, George S, Mindry D, Collins M, et al. "Whatever I Have, I Have Made by Coming into this Profession": The Intersection of Resources, Agency, and Achievements in Pathways to Sex Work in Kolkata, India. Archives of Sexual Behavior. 2015.

10. Bekker LG, Johnson L, Cowan F, Overs C, Besada D, Hillier S, et al. HIV and sex workers 2: Combination HIV prevention for female sex workers: what is the evidence? Lancet 2015; :. 2015;385: 72-87. but are available from the corresponding author on reasonable request. Any interested individual or organization can contact the corresponding author to access to the data.

Competing interests: The authors declare as there is no conflict of interest on this article

Funding: No funding was received

11. McGlynn C. John Stuart Mill on prostitution : radical sentiments, liberal proscriptions. Nineteenth-century gender studies. 2012;8(2).

12. Abel GM. A decade of decriminalization: Sex work 'down under' but not underground. Criminology and Criminal Justice. 2014;14(580).

13. Rekart ML. Sex-work harm reduction. Lancet. 2005;366:2123-34.

14. Ajzen I. Perceived Behavioral Control, Self-Efficacy, Locus of Control, and the Theory of Planned Behavior. JOURNAL OF APPLIED SOCIAL PSYCHOLOGY. 2002; 32(4):665-83.

15. Baker LM, Dalla RL, Williamson C. Exiting Prostitution: An Integrated Model. Violence Against Women. 2010;16(5):579-600.

16. Cimino AN. Developing and Testing a Theory of Intentions to Exit Street-level Prostitution: A Mixed Methods Study: Arizona State University; 2013.

17. Dodsworth J. Pathways through Sex Work: Childhood Experiences and Adult Identities. British Journal of Social Work. 2011:1-18.

18. Hickle KE. Getting out: A Qualitative Exploration of the Exiting Experience Among Former Sex Workers and Adult Sex Trafficking Victims Arizona State University; 2014.

19. Bowen RR. Squaring Up: Experiences of Transition from Off-Street Sex Work to Square Work and Duality-Concurrent Involvement in Both-in Vancouver, BC. CRS/RCS. 2015;52(4):429-49.

20. Oosthuyzen TN. Identifying 'everyday' challenges faced by former South African street-based prostituted women using Photovoice and the risks for re-entry. Cape Town: University of Cape Town; 214.

21. Thorlby K, Elaine. Global Perspectives on Sustainable Exit from Prostitution: An analysis of social enterprise approaches adopted by faith-based projects supporting women to leave prostitution: Durham University; 2015.

22. Scoular J, Carline A. Saving fallen women now? Critical perspectives on engagement and support orders and their policy of forced welfarism. Social Policy and Society. 2015;14(1):103-12.

23. Hakala S, Keller M. "I can"t carry on like this": A feminist perspective on the process of exiting sex 
work in a South African context: University of Cape Town.

24. DKT Ethiopia. Report on Sex Workers Population Size Estimation in Seventeen Towns of Ethiopia 2012.

25. Heckathorn DD. Respondent Driven Sampling II: driving valid population estimate from chain referal samples of hidden population. social Problems. 2002;49(1):11-34.

26. Heckathorn DD. Respondent-Driven Sampling: Author. A New Approach to the Study of Hidden Populations. 1997;44.

27. Yzer MC. Perceived Behavioral Control in Reasoned ActionTheory: A Dual-Aspect Interpretation. The Annals of the American Academy of Political and Social Science. 2012(640):101-17.

28. C. Manopaiboon, R. E. Bunnell, P. H. Kilmarx, S. Chaikummao, K. Limpakarnjanarat, S. Supawitkul, et al. Leaving sex work: Barriers, facilitating factors and consequences for female sex workers in northern Thailand. AIDS Care. 2003;15(1):39-52.
29. Hwang S-L, Bedford O. Juveniles' motivations for remaining in prostitution. Psychology of Women Quarterly, (),. 2004;28 (2004):136-46.

30. Tsai LC, Witte SS, Aira T, Riedel M, Hwang HG, Ssewamala $F$. There is no other option; we have to feed our families...who else would do it?": The Financial Lives of Women Engaging in Sex Work in Ulaanbaatar, Mongolia. Global Journal of Health Science. 2013;5(5):41-50.

31. Dalla RL. "You can't hustle all you rlife": an exploratory investigation of the exit process among street-level prostituted women. Psychology of Women Quarterly 2006;30:276-90.

32. Sanders T. Becoming an Ex-Sex WorkerMaking Transitions Out of a Deviant Career. Feminist Criminology. 2007;2(1):74-95.

33. Oselin SS. Weighing the consequences of a deviant career: Factors leading to an exit from prostitution. Sociological Perspectives. 2010;53(4):527-49.

34. Mansson SA, Hedin UC. Breaking the Matthew effect on women leaving prostitution. international journal of social welfare. 1999;8:67-77. 